\title{
Identification of the major T-cell antigens present in the Brucella melitensis B115 protein preparation, Brucellergene OCB
}

\author{
P. A. DENOEL, T. K.-O. VO, V. E. WEYNANTS, A. TIBOR, D. GILSON, M. S. ZYGMUNT*, \\ J. N. LIMET and J.-J. LETESSON
}

Laboratoire de Microbiologie et d'Immunologie, UR Biologie Moléculaire, Facultés Universitaires Notre-Dame de la Paix, 61 rue de Bruxelles, B-5000 Namur, Belgium and * Laboratoire de Pathologie Infectieuse et Immunologie, Institut National de la Recherche Agronomique, 37380 Nouzilly, France

\begin{abstract}
Brucellergene is a commercial allergen prepared from Brucella melitensis strain B115 and containing at least 20 cytoplasmic proteins. These proteins were separated by SDSPAGE. The unstained gel was divided into 18 fractions and proteins were eluted from the gel fractions. The capacity of the separated proteins to elicit delayed-type hypersensitivity (DTH) in infected guinea-pigs or to induce the production of interferon- $\gamma($ IFN- $\gamma$ ) by blood cells from infected cattle was evaluated. The biological activity of the corresponding protein fractions blotted on to nitrocellulose was measured in a lymphocyte blastogenesis assay. Among the 18 fractions tested, two - spanning the mol. wt ranges 17-22 (fraction 8) and 35-42-kDa (fraction 17) - showed the maximum biological activity in the three tests. These fractions contain two antigens, the Brucella bacterioferritin (BFR) and P39 proteins. Both proteins are good candidates for the detection of cellular immunity to Brucella.
\end{abstract}

\section{Introduction}

Brucella spp. are the agents of brucellosis. As a facultative intracellular pathogen, Brucella elicits a cellular immune response as well as an antibody response, and there is evidence that protection from infection and elimination of this pathogen require cellmediated immune responses (CMI) $[1,2]$.

Serological tests that detect the presence of antilipopolysaccharide (LPS) antibodies are the main tests used for the diagnosis of brucellosis. However, these diagnostic tools do not allow the detection of all infected animals, such as, for example, recently or chronically infected animals. Moreover, a more problematic aspect of serological diagnosis has emerged recently: false-positive serological reactions $[3,4]$ caused by the antigenic relationships between Brucella LPS and LPS expressed by other gram-negative bacteria $[5,6]$ mainly by Yersinia enterocolitica $\mathrm{O} 9$. An alternative is the detection of the antiprotein antibody response with specific proteins as antigens [7-12]. However, the antiprotein response is far too heterogeneous and too delayed to be of great help in serological diagnosis [7, 12, 13].

Received 30 Jan. 1997; accepted 17 Feb. 1997. Corresponding author: Dr P. A. Denoel.
The delayed-type hypersensitivity (DTH) test has been widely used for the diagnosis of brucellosis in ruminants. It constitutes a useful diagnostic tool complementary to serology, and various allergens from different Brucella species have been prepared for this purpose [14-16]. Allergic diagnosis is used in a number of countries, but the type and specificity of reactions induced in animals, as well as the sensitivity of the methods, are variable.

Among the allergens used, the Brucelline developed by the INRA (France) and commercialised by RhôneMérieux (Brucellergene ${ }^{\circledR}$ ) consists of a mixture of 20-30 cytoplasmic proteins and is prepared from a rough (R) strain of $B$. melitensis B115 [15]. This allergen has proved to be valuable in detecting Brucella-infected cattle [17, 18]. However, although a $\mathrm{R}$ strain of Brucella was used to prepare the Brucellergene, this strain is not devoid of LPS-like molecules [19]. The presence of LPS antigen in the allergen may perturb the DTH reaction and induce an antibody response which might interfere with subsequent serological tests. Furthermore, the variation in protein content of the various batches may be one cause of the heterogeneity of the DTH response. The production of a recombinant allergen composed of a few specific antigens and devoid of LPS molecules should help the diagnosis of brucellosis. 
Interferon- $\gamma$ (IFN- $\gamma)$ plays a crucial role in the resolution of Brucella infection, as demonstrated by its ability to activate antibacterial functions of infected macrophages. Moreover, B. abortus induces a type 1 cytokine pattern $[20,21]$. Therefore, identification of proteins inducing IFN- $\gamma$ production could lead to the use of new antigens in powerful diagnostic tests based on an in-vitro antigen-specific IFN- $\gamma$ production [3].

The study and identification of antigens eliciting CMI would help both specific diagnosis and vaccination against brucellosis. This study describes the fractionation of Brucellergene and the testing of the resulting fractions in three assays of cellular immunity: DTH assay in infected guinea-pigs, lymphocyte proliferation (LB assay) and in-vitro antigen-specific IFN- $\gamma$ production by blood cells from infected cattle.

\section{Materials and methods}

\section{Chemicals and reagents}

Brucellergene OCB (Rhone-Mérieux, batch 26N151) was used throughout the experiments. Donkey antirabbit immunoglobulins (Ig) and sheep anti-mouse Ig antisera conjugated to peroxidase, and ethyl $-\left[{ }^{3} \mathrm{H}\right]$ thymidine were from Amersham. Phytohaemagglutinin (PHA) was from Sigma.

\section{Monoclonal antibodies and antiserum}

The production of anti-P39 monoclonal antibodies (MAbs) was as described previously [18]. Bacterioferritin (BFR) was prepared as described previously [8]. One rabbit was immunised with $50 \mu \mathrm{g}$ of BFR, initially in the presence of complete Freund's adjuvant (CFA) and on day 15 with incomplete FA. The rabbit was bled 1 week after the last injection.

\section{Fractionation of Brucellergene}

Proteins of Brucellergene were separated by SDSPAGE on $12 \%$ gel. The unstained gel was then cut into 20 sections of $3.3 \mathrm{~mm}$. These gel sections were chopped in $1 \mathrm{ml}$ of phosphate-buffered saline (PBS) $0.2 \mathrm{mM}$ phenylmethylsulphonyl fluoride (PMSF) (Sigma), 5mM EDTA and proteins were allowed to diffuse out of the gel for $24 \mathrm{~h}$. The supernate containing the eluted proteins was harvested and then dialysed against PBS $0.2 \mathrm{mM}$ PMSF, $5 \mathrm{mM}$ EDTA to eliminate residual SDS. These preparations constituted the protein fractions used in DTH and in-vitro antigen-specific IFN- $\gamma$ production assays. The protein concentration was measured with Micro BCA protein assay reagent (Pierce, Rockford, IL, USA) or by densitometry analysis of silver stained gels with a Visage 110 scanner and with the Bio Image Electrophoresis Analyser 4.6B Whole Band 2.4 software (Millipore). Bovine serum albumin (BSA) was used as a standard.

\section{SDS-PAGE analysis, immunoblotting and preparation of blots}

Protein fractions were analysed on polyacrylamide $16 \%$ SDS slab gels. The separated proteins were then either silver stained or transferred electrophoretically on to nitrocellulose as previously described $[10,22]$. Nitrocellulose membranes were used for immunoblotting or cut into 20 fractions for LB assay.

Immunoblotting with anti-P39 MAbs and anti-BFR antiserum was performed as described previously $[10,22]$.

The preparation of blots for LB assay was done as described by Young and Lamb [23]. Briefly, the blots were rinsed with PBS and then allowed to dry in air. The protein-containing portion of the nitrocellulose was then cut into 20 sections. The sections were solubilised with $250 \mu$ of dimethylsulphoxide (Merck), then precipitated with $250 \mu \mathrm{l}$ of $\mathrm{NaHCO}_{3} / \mathrm{Na}_{2} \mathrm{CO}_{3} 0.05 \mathrm{mM}$ buffer. The precipitate was resuspended in PBS and this suspension was used in the LB assay.

\section{DTH assay in infected guinea-pigs}

Guinea-pigs of the Hartley strain were infected subcutaneously by injection of $2 \times 10^{6}$ live cells of $B$. abortus 544 or $Y$. enterocolitica 09 . Three weeks after infection, guinea-pigs were skin tested by the intradermal injection of 1 or $3 \mu \mathrm{g}$ of Brucellergene in $100 \mu \mathrm{l}$ of PBS; $1 \mu \mathrm{g}$ of different protein fractions of Brucellergene, in $100 \mu 1$, was injected intradermally. Each guinea-pig received in parallel an injection of $1 \mu \mathrm{g}$ of Brucellergene and $100 \mu \mathrm{l}$ of PBS as positive and negative controls, respectively. A maximum of eight injections were done on the flanks so that each guinea-pig received both control antigens and six fractions. The increase in skin thickness was measured 1,24 and $48 \mathrm{~h}$ after injection. The data presented are the results of four experiments. Results were expressed as mean increase in skin thickness $(\mathrm{mm})$ and SD or as the percentage of Brucellergene reactivity.

\section{Lymphocyte blastogenesis (LB) assay}

LB assay with peripheral blood mononuclear cells (PBMC) from naturally infected cows was performed as described previously [18]. Briefly, antigens were added $\left(1 \mu \mathrm{g} /\right.$ well) to cultured PBMC $\left(10^{5}\right.$ cells/well) at the initiation of the cultures. Whole Brucellergene and PHA ( $1 \mu \mathrm{g} /$ well) were used as comparison standard and positive control, respectively. After 6 days, cultures were pulsed with $0.8 \mu \mathrm{Ci}\left[{ }^{3} \mathrm{H}\right]$ thymidine/ well for $18 \mathrm{~h}$. Incorporation of radioactivity was measured by liquid scintillation counting (1205 betaplate, Wallac, Pharmacia). Stimulation indices (SI) were calculated by dividing the $\mathrm{cpm}$ of stimulated cultures by the cpm of non-stimulated culture. Results were expressed either as SI (SD) or as the percentage of Brucellergene reactivity. 
In-vitro antigen-specific IFN- $\gamma$ production assay (IFN assay)

The IFN assay was performed as described previously [3]. Briefly, $500 \mu \mathrm{l}$ of heparinised blood from two naturally infected cows was stimulated in vitro with $100 \mu \mathrm{l}$ of PBS containing $5 \mu \mathrm{g}$ of antigen for $24 \mathrm{~h}$ before harvesting and testing the supernate. Bovine IFN- $\gamma$ was assayed with an ELISA kit (IDEXX, Paris, France) according to the manufacturer's instructions. SI were calculated by dividing the optical density of cultures with antigen by the optical density of control culture. Results were expressed either as SI (SD) or as percentage of Brucellergene reactivity.

\section{Results}

\section{Fractionation of Brucellergene}

Fractions of Brucellergene were analysed by SDSPAGE and silver stained (Fig. 1a). Silver staining revealed one or two major bands in each lane, showing
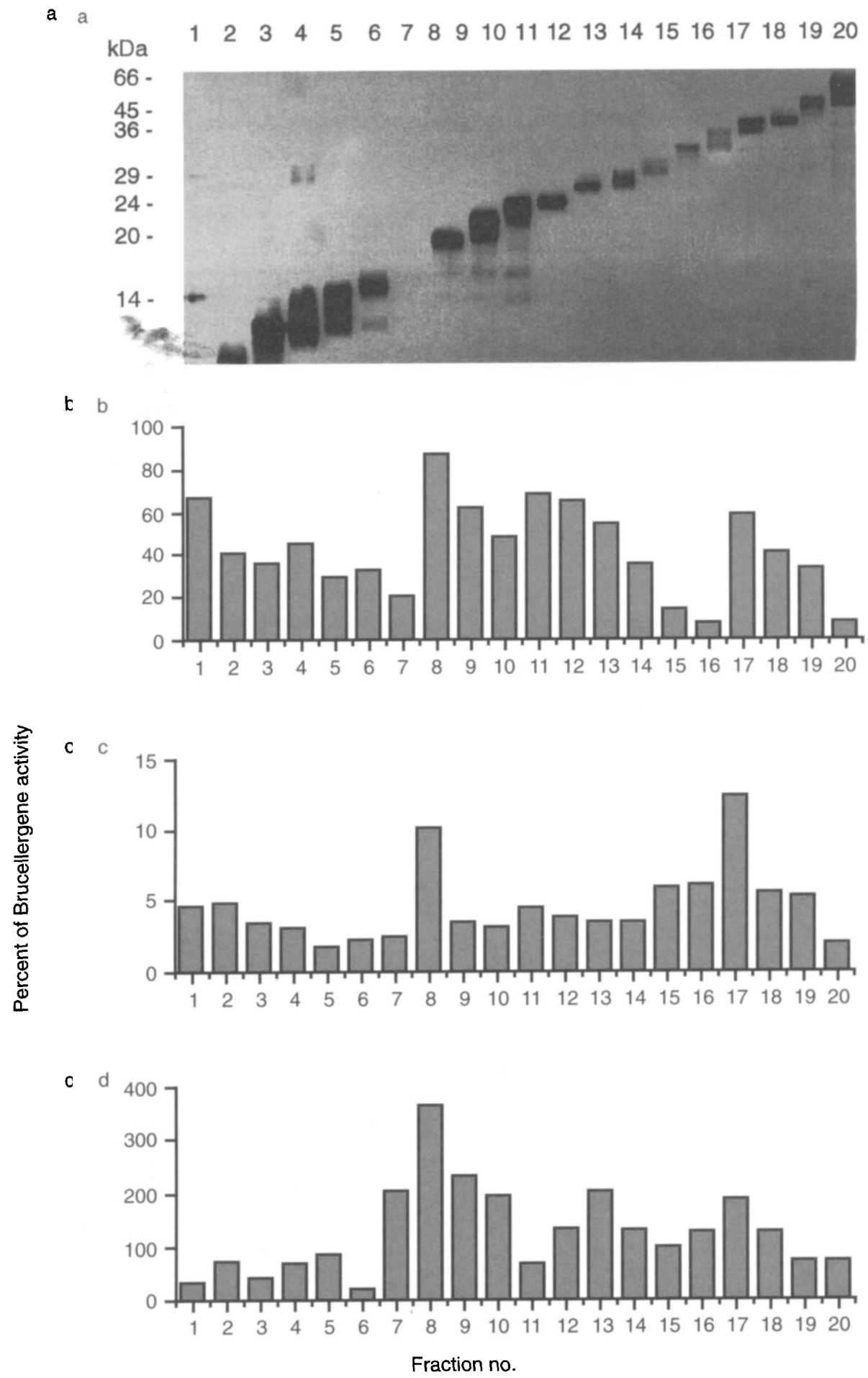

Fig. 1. (a) SDS-PAGE analysis of the 20 fractions obtained from Brucellergene. The reactivity of these fractions in (b) DTH assay; (c) LB assay; (d) IFN assay is expressed as a percentage of Brucellergene reactivity. 
that each fraction contained at least one or two major proteins with weak contamination by other proteins.

\section{Activity of the protein fractions in DTH assay}

The 20 Brucellergene fractions were injected into Brucella-, Yersinia- and non-infected guinea-pigs, and the increase in skin thickness was measured $24 \mathrm{~h}$ after injection (Table 1). The mean increase in skin thickness at the site of injection of Brucellergene and PBS was 1.1 (SD 0.2) $\mathrm{mm}$ and 0.2 (SD 0.05) $\mathrm{mm}$, respectively. None of the 20 fractions was able to induce a significant increase in skin thickness in the non-infected animals.

Among the 20 fractions tested none was able to induce an increase in skin thickness superior or equal to the one induced by the Brucellergene. However, fractions 8-9, $11-13$ and 17 were of most interest as they induced reactions corresponding to $50-85 \%$ of that induced by Brucellergene (Fig. 1b). None of these fractions induced DTH in Yersinia-infected animals. An intense reaction was also induced in Brucella-infected animals by fraction 1 , but the reaction was even more intense $1 \mathrm{~h}$ after injection. This kind of reaction does not correspond to DTH and this fraction was not considered as giving a positive result.

\section{Activity of the protein fractions in lymphocyte proliferation}

PBMC from three Brucella-infected cows and from a non-infected cow were used to test the 20 fractions of Brucellergene (Fig. 1b). PBMC from the non-infected cow did not proliferate in response to any of the fractions nor to Brucellergene. PBMC from non-

Table 1. Activity of the 20 protein fractions in DTH, LB and IFN assays

\begin{tabular}{|c|c|c|c|c|c|c|}
\hline \multirow[b]{2}{*}{ Fraction no. } & \multicolumn{2}{|c|}{$\begin{array}{l}\text { DTH assay } \\
(\mathrm{mm})\end{array}$} & \multicolumn{2}{|c|}{$\begin{array}{l}\text { LB assay } \\
\text { (SI) }\end{array}$} & \multicolumn{2}{|c|}{$\begin{array}{l}\text { IFN assay } \\
\quad(\mathrm{SI})\end{array}$} \\
\hline & mean & SD & mean & SD & mean & SD \\
\hline Brucellergene & 1.1 & 0.2 & 217.0 & 22.7 & 6.4 & 1.5 \\
\hline PBS & 0.2 & 0.1 & ND & ND & 1.0 & 1.1 \\
\hline Nitrocellulose & ND & ND & 1.3 & 0.3 & ND & ND \\
\hline 1 & 0.7 & 0.4 & 9.8 & 1.7 & 1.7 & 0.3 \\
\hline 2 & 0.4 & 0.1 & 10.2 & 2.9 & 4.8 & 0.3 \\
\hline 3 & 0.4 & 0.0 & 7.2 & 1.1 & 2.6 & 0.2 \\
\hline 4 & 0.5 & 0.2 & 6.6 & 1.0 & 4.4 & 0.5 \\
\hline 5 & 0.3 & 0.2 & 3.8 & 0.3 & 5.8 & 0.7 \\
\hline 6 & 0.4 & 0.2 & 4.7 & 0.1 & 1.1 & 0.1 \\
\hline 7 & 0.2 & 0.1 & 5.1 & 1.1 & 13.9 & 2.3 \\
\hline 8 & 1.0 & 0.2 & 21.6 & 2.1 & 24.7 & 0.6 \\
\hline 9 & 0.7 & 0.0 & 7.4 & 0.6 & 15.7 & 0.6 \\
\hline 10 & 0.5 & 0.1 & 6.5 & 0.9 & 13.1 & 1.1 \\
\hline 11 & 0.7 & 0.6 & 9.5 & 0.7 & 4.7 & 0.8 \\
\hline 12 & 0.7 & 0.1 & 8.1 & 2.9 & 8.9 & 0.0 \\
\hline 13 & 0.6 & 0.1 & 7.5 & 0.7 & 13.8 & 2.3 \\
\hline 14 & 0.4 & 0.1 & 7.2 & 1.4 & 8.8 & 0.9 \\
\hline 15 & 0.2 & 0.1 & 12.3 & 2.3 & 6.6 & 0.2 \\
\hline 16 & 0.1 & 0.1 & 12.7 & 3.6 & 8.5 & 0.3 \\
\hline 17 & 0.7 & 0.1 & 26.2 & 3.3 & 12.9 & 1.3 \\
\hline 18 & 0.5 & 0.2 & 11.8 & 1.8 & 8.6 & 1.1 \\
\hline 19 & 0.4 & 0.4 & 11.1 & 3.6 & 4.9 & 0.4 \\
\hline 20 & 0.1 & 0.1 & 4.2 & 1.3 & 4.9 & 1.1 \\
\hline
\end{tabular}

infected and infected cows did not respond to nitrocellulose alone $(\mathrm{SI}=1.3)$. However, PMBC from the infected cows proliferated strongly in response to Brucellergene, as well as to fractions 8 and 17 with SI values of 217 (SD 22.7), 21.6 (SD 2.1) and 26.2 (SD 3.3) respectively (Table 1 ).

None of the 20 fractions tested was able to induce a reaction $>15 \%$ of that induced by Brucellergene (Fig. 1c). However, the proliferations observed with fractions 8 and 17 were approximately double those induced by the other fractions.

\section{Activity of the protein fractions in IFN assay}

Blood samples from two Brucella-infected cows were tested for IFN- $\gamma$ production upon Brucellergene stimulation (Table 1). The mean SI observed was 6.4 (SD 1.5). Among the 20 fractions tested, 10 fractions induced an IFN- $\gamma$ production superior to that induced by Brucellergene. The maximum SI observed with the blood sample from a non-infected animal was 1.9.

Fractions $7-10,13$ and 17 induced the most intense IFN- $\gamma$ production $(12.9<\mathrm{SI}<24.7)$ (Fig. 1d). The stimulation of IFN- $\gamma$ production by blood cells of infected animals induced by these fractions was nearly always doubly superior to that induced by Brucellergene.

\section{Western blot analysis of fractions 8 and 17}

Fractions 8 and 17 seem to be relevant T-cell antigens, as they induced highly positive reactions in the three tests performed. Fraction 8 contained proteins of 18 $20 \mathrm{kDa}$ and fraction 17 contained proteins of 36 $40 \mathrm{kDa}$. Immunoblot analysis with anti-BFR polyclonal antiserum and anti-P39 MAb following SDS-PAGE of fractions 8 and 17, respectively, revealed one band in each fraction (Fig. 2). This indicates that one of the

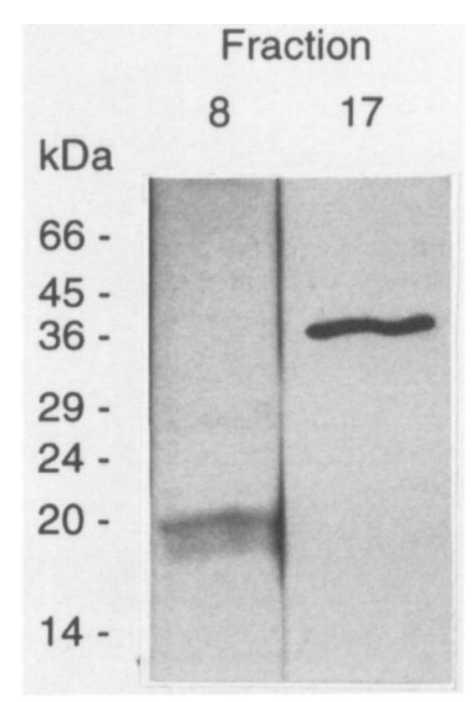

Fig. 2. Immunoblotting of fraction 8 with anti-BFR antiserum and fraction 17 with anti-P39 MAb. 
proteins present in fraction 8 was BFR and that P39 was present in fraction 17.

\section{Discussion}

Brucellergene, a cytoplasmic protein preparation of $B$. melitensis B115, has proved valuable in detecting Brucella-infected cattle by skin testing [17, 18]. However, the presence of LPS in the allergen could sensitise tested animals and induce an antibody response that could be detected by subsequent serological tests. The method of preparation leads to a different protein composition in the different batches produced. Identifying the T-immunodominant protein contained in Brucellergene could help design a new allergen of defined composition. Moreover, as Brucella induces a type 1 cytokine pattern $[20,21]$, the identification of specific antigens that preferentially induce a Th1 subset response is an important element in designing new molecular candidate vaccines.

By fractionating Brucellergene into 20 fractions, it was possible to identify the major T-cell antigens present in this protein preparation. Fraction 17 induced positive DTH reaction in infected guinea-pigs, lymphocyte proliferation and stimulated the production of IFN- $\gamma$ by blood cells of infected animals. This fraction contained P39, a protein antigen that was shown previously to be immunodominant and a good DTH inducer in infected cattle. Fraction 8 was a strong inducer of DTH in infected guinea-pigs and of IFN- $\gamma$ production by blood cells of infected cattle. It also induced the proliferation of lymphocytes from infected cattle. This antigen contained the BFR protein of Brucella. We believe that this protein is responsible, in great part, for the activity of this fraction. Indeed, preliminary results obtained with purified recombinant BFR indicated that this protein induced DTH reactions in infected guinea-pigs and the production of IFN- $\gamma$ by blood cells of infected cattle (data not shown). Fractions 10-13 also contained T-cell antigens, but the reactions observed in the three tests were less intense than that induced by fractions 8 and 17 . These fractions (10-13) contained $25-30-\mathrm{kDa}$ proteins that have not yet been identified.

In order to set up a new specific diagnostic test, the specificity of both antigens should be measured. A previous study showed that P39 is a specific antigen by performing DTH and LB assays on cattle infected with bacteria cross-reacting with Brucella. The specificity of BFR is more questionable, as this protein is highly conserved among bacterial species. However, the presence of less conserved regions in the proteins which could correspond to specific epitopes has been described previously [22]. Moreover, BFR did not induce any DTH reaction in guinea-pigs infected with $Y$. enterocolitica $\mathrm{O9}$.
Some fractionated protein antigens were able to induce positive reactions of the same (Fig. 1b) or greater (Fig. 1d) intensity than Brucellergene in DTH and IFN assays. However, the reactions induced in LB assay did not exceed $15 \%$ of that induced by Brucellergene. One explanation is that the doses of fractionated proteins could not have been adjusted and were probably less than the dose of Brucellergene used. Despite this difference of intensities, the profile of reactions observed was the same in the three tests and resembled previously reported lymphocyte proliferation profiles [24-27].

Because of the kind of gel resolution used in the present experiments, no fraction containing proteins $<16 \mathrm{kDa}$ was obtained. This explains why it was not possible to identify major T-cell antigens of lower mol. wts. Indeed, a 12-kDa protein (L7/L12), has been shown to be a major component in the antigenicity of Brucellergene [28]. This antigen was probably not present in our protein fractions.

Fractionation of Brucella proteins and measurement of their ability to stimulate lymphocyte proliferation has been reported previously [25-27, 29] but only a few immunodominant protein antigens of Brucella eliciting a cellular immune response in infected cattle have been clearly identified $[27,28,30]$. The ability of soluble Brucella protein fractions to induce the production of IFN- $\gamma$ by primed murine T-lymphocytes has been demonstrated [31]. The present study clearly identified two cellular immunodominant antigens by performing DTH assays in an animal model and by measuring lymphocyte proliferation and IFN- $\gamma$ production with cells of infected cattle. The identification of these two antigens could contribute to the improvement of a skin test or IFN assay which can be standardised, allowing better diagnostic and epidemiological performance. Also, these two inducers of IFN- $\gamma$ could lead to the design of new molecular candidate vaccines, as has been done with another Brucella immunodominant T-cell antigen [32].

P. D. holds a specialisation bursary from the IRSIA/FRIA (no. 910622). We thank D. Prozzi for helpful advice, G. Houbeau and H. Bawin for their help with the guinea-pig experiments and E. Delaive for performing the densitometry analysis. This research was supported in parts by funds provided by the Institute for the Encouragement of Research in Industry and Agriculture (IRSIA).

\section{References}

1. Elberg SS. Immunity to Brucella infection. Medicine (Baltimore) 1973; 52: 339-356.

2. Smith R. T lymphocyte-mediated mechanisms of acquired protective immunity against brucellosis in cattle. In: Adams LG (ed) Advances in brucellosis research. College Station, Texas A \& M University Press. 1990: 164-190.

3. Weynants V, Godfroid J, Limbourg B, Saegerman C, Letesson $\mathrm{J}-\mathrm{J}$. Specific bovine brucellosis diagnosis based on in vitro antigen-specific gamma interferon production. $J$ Clin Microbiol 1995; 33: 706-712. 
4. Benet JJ, Massard C, Garin B. Réactions sérologiques atypiques dans le dépistage de la brucellose bovine. Epidémiol Santé Anim 1991; 19: 97.

5. Corbel MJ. Recent advances in the study of Brucella antigens and their serological cross-reactions. Vet Bull 1985; 55: $927-$ 942 .

6. Corbel MJ, Stuart FA, Brewer RA. Observations on serological cross-reactions between smooth Brucella species and organisms of other genera. Dev Biol Stand 1983; 56: 341-348.

7. Cloeckaert A, Kerkhofs P, Limet JN. Antibody response to Brucella outer membrane proteins in bovine brucellosis: immunoblot analysis and competitive enzyme-linked immunosorbent assay using monoclonal antibodies. $J$ Clin Microbiol 1992; 30: 3168-3174.

8. Zygmunt MS, Gilbert FB, Dubray G. Purification, characterization and seroactivity of a 20 -kilodalton Brucella protein antigen. $J$ Clin Microbiol 1992; 30: 2662-2667.

9. Tibor A, Saman E, de Wergifosse P, Cloeckaert A, Limet JN, Letesson J-J. Molecular characterization, occurrence, and immunogenicity in infected sheep and cattle of two minor outer membrane proteins of Brucella abortus. Infect Immun 1996; 64: 100-107.

10. Tibor A, Weynants V, Denoel PA et al. Molecular cloning, nucleotide sequence, and occurrence of a 16.5-kilodalton outer membrane protein of Brucella abortus with similarity to PAL lipoproteins. Infect Immun 1994; 62: 3633-3639.

11. Goldbaum FA, Rubbi CP, Wallach JC, Miguel SE, Baldi PC, Fossati CA. Differentiation between active and inactive human brucellosis by measuring antiprotein humoral immune responses. J Clin Microbiol 1992; 30: 604-607.

12. Limet JN, Cloeckaert A, Bezard G, Van Broeck J, Dubray G. Antibody response to the $89-\mathrm{kDa}$ outer membrane protein of Brucella in bovine brucellosis. J Med Microbiol 1993; 39: 403-407.

13. Leiva Leon JL, de la Rosa M, Plata J, Martinez MJ, JimenezAlonso J. An immunoblotting study of serologic response in patients with acute brucellosis. Diagn Microbiol Infect Dis 1991; 14: 515-518.

14. Hoffmann EM, Shapiro SJ, Nicoletti P. Evaluation of serologic and cellular immune responses of cattle to a nonlipopolysaccharide antigen from Brucella abortus. Am J Vet Res 1990; 51: 216-221.

15. Jones LM, Diaz R, Taylor AG. Characterization of allergens prepared from smooth and rough strains of Brucella melitensis. Br J Exp Pathol 1973; 54: 492-508.

16. Smith R, Adams LG, Ficht TA, Sowa BA, Wu AM. Immunogenicity of subcellular fractions of Brucella abortus: measurement by in vitro lymphocyte proliferative responses. Vet Immunol Immunopathol 1990; 25: 83-97.

17. Fensterbank R. Le diagnostic allergique de la brucellose. Bull Acad Vét France 1982; 55: 47-52.

18. Denoel PA, Vo TK-O, Tibor A et al. Characterization, occurrence, and molecular cloning of a 39-kilodalton Brucella abortus cytoplasmic protein immunodominant in cattle. Infect Immun 1997; 65: 495-502.
19. Cloeckaert A, Zygmunt MS, Nicolle J-C, Dubray G, Limet JN $\mathrm{O}$-chain expression in the rough Brucella melitensis strain B115: induction of O-polysaccharide-specific monoclonal antibodies and intracellular localization demonstrated by immunoelectron microscopy. J Gen Microbiol 1992; 138: 1211-1219.

20. Zaitseva MB, Golding $\mathrm{H}$, Betts $\mathrm{M}$ et al. Human peripheral blood $\mathrm{CD}^{+}$and $\mathrm{CD}^{+} \mathrm{T}$ cells express Th1-like cytokine mRNA and proteins following in vitro stimulation with heatinactivated Brucella abortus. Infect Immun 1995; 63: 2720 2728 .

21. Oliveira SC, Splitter GA. CD8 ${ }^{+}$type $1 \mathrm{CD} 44^{\text {hi }} \mathrm{CD} 45 \mathrm{RB}^{\mathrm{lo}} \mathrm{T}$ lymphocytes control intracellular Brucella abortus infection as demonstrated in major histocompatibility complex class I- and class II-deficient mice. Eur J Immunol 1995; 25: 2551-2557.

22. Denoel PA, Zygmunt MS, Weynants VE et al. Cloning and sequencing of the bacterioferritin gene of Brucella melitensis 16M strain. FEBS Lett 1995; 361: 238-242.

23. Young DB, Lamb JR. T lymphocytes respond to solid-phase antigen: a novel approach to the molecular analysis of cellular immunity. Immunology 1986; 59: 167-171.

24. Stevens MG, Olsen SC, Cheville NF. Lymphocyte proliferation in response to immunodominant antigens of Brucella abortus 2308 and RB51 in strain 2308-infected cattle. Infect Immun 1994; 62: 4646-4649.

25. Stevens MG, Olsen SC, Pugh GW, Brees D. Comparison of immune responses and resistance to brucellosis in mice vaccinated with Brucella abortus 19 or RB51. Infect Immun 1995; 63: 264-270.

26. Brooks-Worrell BM, Splitter GA. Sodium dodecyl sulfate- and salt-extracted antigens from various Brucella species induce proliferation of bovine lymphocytes. Infect Immun 1992; 60: 2136-2138.

27. Brooks-Worrell BM, Splitter GA. Antigens of Brucella abortus immunodominant for bovine lymphocytes as identified by oneand two-dimensional cellular immunoblotting. Infect Immun 1992; 60: 2459-2464

28. Bachrach G, Banai M, Bardenstein S, Hoida G, Genizi A Bercovier $\mathrm{H}$. Brucella ribosomal protein $\mathrm{L} 7 / \mathrm{L} 12$ is a major component in the antigenicity of brucellin INRA for delayedtype hypersensitivity in Brucella-sensitized guinea pigs. Infect Immun 1994; 62: 5361-5366.

29. Stevens MG, Olsen SC, Pugh GW. Lymphocyte proliferation in response to Brucella abortus 2308 or RB51 antigens in mice infected with strain 2308, RB51, or 19. Infect Immun 1994; 62: 4659-4663.

30. Oliveira SC, Splitter GA. Subcloning and expression of the Brucella abortus L7/L12 ribosomal gene and T-lymphocyte recognition of the recombinant protein. Infect Immun 1994; 62: 5201-5204.

31. Zhan Y, Yang J, Cheers C. Cytokine response of T-cell subsets from Brucella abortus-infected mice to soluble Brucella proteins. Infect Immun 1993; 61: 2841-2847.

32. Oliveira SC, Splitter GA. Immunization of mice with recombinant $\mathrm{L} 7 / \mathrm{L} 12$ ribosomal protein confers protection against Brucella abortus infection. Vaccine 1996; 14: 959-962. 